\title{
Solution of Nonlinear Systems of Equations via Metaheuristics
}

\author{
Sangeeta Pant \\ Department of Mathematics \\ University of Petroleum \& Energy Studies, Dehradun, India \\ Corresponding author: pant.sangeet@gmail.com \\ Anuj Kumar \\ Department of Mathematics \\ University of Petroleum \& Energy Studies, Dehradun, India \\ Mangey Ram \\ Department of Mathematics; Computer Science \& Engineering \\ Graphic Era Deemed to be University, Dehradun, India
}

(Received January 12, 2019; Accepted July 11, 2019)

\begin{abstract}
A framework devoted to the solution of nonlinear systems of equations using grey wolf optimization algorithm (GWO) and a multi-objective particle swarm optimization algorithm (MOPSO) is presented in this work. Due to several numerical issues and very high computational complexity, it is hard to find the solution of such a complex nonlinear system of equations. It then explains that the problem of solution to a system of nonlinear equations can be simplified by viewing it as an optimization problem and solutions can be obtained by applying a nature inspired optimization technique. The results achieved are compared with classical as well as new techniques established in the literature. The proposed framework also seems to be very effective for the problems of system of non-linear equations arising in the various fields of science. For this purpose, the problem of neurophysiology application and the problem of combustion of hydrocarbons are considered for testing. Empirical results show that the presented framework is bright to deal with the high dimensional equations system.
\end{abstract}

Keywords- Optimization; Metaheuristic, Grey wolf optimizer algorithm (GWO), Particle swarm optimization (PSO), Nonlinear equation system.

\section{Introduction}

A fundamental task in reliability engineering (Ram, 2013) and sciences, is finding the solutions of the system of nonlinear equations. The system of nonlinear equations can also arise in many domains like medicine, engineering, chemistry, robotics etc., which have their practical importance in human life. The task of finding the solutions is sometimes further complicated by adding a number of inequality and/or variable bound constraints. The problem of finding all solutions of a system of equation which is nonlinearly constrained is having very high computational complexity due to several numerical concerns and so it is non-deterministic polynomial-time hard (NP-hard) in nature. At the same time, there may be exponentially many such solutions (Horst et al., 1995). There exists a large frame of literature on methods to the solving systems of equations. According to Hentenryck et al. (1997), these methods fall within the following two broad classes: (i) Interval methods, though they are robust, but at the same time they are slow; (ii) Continuation methods, which are in effect for the problems in which, the total degree is not too high. For many years, and even today, the problems of solution to system of nonlinear equations were solved by these methods, though these approaches are inadequate for hard problems with unusual convergence pattern. 
International Journal of Mathematical, Engineering and Management Sciences

Vol. 4, No. 5, 1108-1126, 2019

https://dx.doi.org/10.33889/IJMEMS.2019.4.5-088

The nonlinear system of equation is defined as

$$
f(t)=\left[\begin{array}{l}
f_{1}(t) \\
f_{2}(t) \\
\cdot \\
f_{m}(t)
\end{array}\right]
$$

where $t=\left(t_{1}, t_{2}, \ldots . ., t_{m}\right)$ refers to $m$ equations and $m$ variables. $f_{1}, f_{2}, \ldots \ldots, f_{m}$ are nonlinear functions, some of which can be linear but not all. If for some value of $\left(t_{1}, t_{2}, \ldots ., t_{m}\right)$ every equation in the nonlinear system is zero then it is termed as a solution for nonlinear system of equations. Nonlinear equation systems can be solved by several ways (Denis, 1967a, 1968b, 1971c; Ortega and Rheinboldt, 1970; Denis and Wolkowicz, 1993; Brezinski, 1997; Denis et al., 1999, Grosan et al., 2006). Some of the popular techniques are Secant method (Denis and Wolkowicz, 1993), Broyden's method (Broyden, 1965; Press et.al., 2002), Effati and Nazemi method (Effati and Nazemi, 2005), Newton's method. These nonlinear algebraic problems can also be solved by converting them into optimization problems. Thus; numerical optimization procedures such as nature inspired algorithm can be used as a tool for the robust solutions of this kind of problem (Maranas and Floudas, 1995; Grosan and Abraham, 2008; Platt, 2014, 2015).

The journey of a modern man from a troglodyte is due to human nature to try to unfold the mysteries of nature to improve the lives of human beings. Few years back we even can't think that school of fish, genes, nature of bat or ant can be used to design optimization algorithms but the nature has the solution of every problem. Researchers working on optimization theory are developing optimization techniques, which are inspired by nature and could be utilized as optimization tools for engineering problems. Metaheuristic optimization techniques are universal nowadays. They have been applied with great success to many real life problems of different domains including reliability optimization, bioinformatics, automotive design engineering (Kumar and Singh, 2008; Park and Pham., 2012; Ram et al., 2013; Singh et al., 2013; Pant et al., 2015a; Yang et al., 2015; Wang et al., 2015; Kumar et al. 2016; Kumar et al., 2017a; Kumar et al., 2017b; Kumar et al., 2017c; Pant et al., 2017a; Pant et al., 2017b; Kumar et al., 2018a; Kumar et al., 2018b; Chaube et al. 2018; Kumar et al., 2019a; Kumar et al., 2019b). Surprisingly, some of them such as the particle swarm optimization (PSO) (Eberhart and Kennedy, 1995); the cuckoo search algorithm (CSA) (Yang and Deb, 2009) and the grey wolf optimizer (GWO) algorithm (Mirjalili et al. 2014) have become very popular among not only mathematicians, but also scientist from different field.

\section{Evolutionary Nonlinear Equations System}

For getting the solution of system of equations $(f)$, we can transform it into a multi-objective or a single objective optimization problem. For transforming it into a multi objective optimization problem, we treat each equation of it as an objective function. The goal of this optimization is the minimization of the difference between the left hand side and the right hand side of the equation in absolute term. Since the right hand side is zero, the objective function is to be given by the absolute value of the left hand side. 
International Journal of Mathematical, Engineering and Management Sciences

Vol. 4, No. 5, 1108-1126, 2019

https://dx.doi.org/10.33889/IJMEMS.2019.4.5-088

The system $(f)$ is then equivalent to

$$
\begin{array}{r}
(f)\left\{\begin{array}{l}
f_{1}\left(t_{1}, t_{2}, \ldots \ldots t_{m}\right)=0 \\
f_{2}\left(t_{1}, t_{2}, \ldots \ldots t_{m}\right)=0 \\
\cdot \\
\cdot \\
f_{m}\left(t_{1}, t_{2}, \ldots \ldots t_{m}\right)=0
\end{array}\right\} \\
\Leftrightarrow(f)^{\prime}\left\{\begin{array}{l}
\min a b s\left(f_{1}\left(t_{1}, t_{2}, \ldots \ldots t_{m}\right)\right) \\
\min a b s\left(f_{2}\left(t_{1}, t_{2}, \ldots \ldots t_{m}\right)\right) \\
\cdot \\
\cdot \\
\min a b s\left(f_{m}\left(t_{1}, t_{2}, \ldots \ldots t_{m}\right)\right)
\end{array}\right\}
\end{array}
$$

While for transforming the given system of equations $(f)$ into a single objective optimization problem one can define the square function $Q(t)=f_{1}{ }^{2}+f_{2}{ }^{2}+\ldots \ldots .+f_{m}{ }^{2}$ or the absolute value function $Q(t)=a b s\left(f_{1}\right)+a b s\left(f_{2}\right)+\ldots \ldots .+a b s\left(f_{m}\right)$ and find the solution of the given system by minimizing the $Q(t)$.

In single objective optimization problem there is only one objective function to optimize while in multi-objective optimization problem there is more than one objective function which have to be optimized simultaneously. In single-objective optimization, solutions can be compared easily. For example, for maximization problem solution ' $X$ ' is better than ' $Y$ ' iff $X>Y$. Due to multicriterion comparison matrix, the solutions in a multi-objective space cannot be compared as the way they compared in case of single-objective optimization. In multi-objective optimization, a solution dominates (better) on another solution iff it shows better or equal objective value on all of the objectives and provide a better value in at least one of the objective functions. The mathematical definition of Pareto dominance Pareto optimal front for a maximization problem is as follows (Coello et al., 2004):

Definition 1. Pareto Dominance: Suppose that there are two vectors such as $\vec{x}=\left(x_{1}, x_{2}, \ldots \ldots ., x_{k}\right)$ and $\vec{y}=\left(y_{1}, y_{2}, \ldots \ldots, y_{k}\right)$ vector $x$ dominates vector $y$ iff $\forall i \in(1,2, \ldots \ldots, k),\left[f\left(x_{i}\right) \geq f\left(y_{i}\right)\right] \wedge\left[\exists i \in 1,2, \ldots \ldots, k: f\left(x_{i}\right)\right]$.

Definition 2. Pareto optimal front: Pareto front can be viewed as the images of the Pareto optimum points in the criterion space.

\subsection{Grey Wolf Optimizer Algorithm (GWO)}

Mirjalili et al. (2014) introduced the Grey Wolf Optimizer (GWO) algorithm in 2014. GWO mimics the hierarchal, chasing, encircling and hunting behavior of grey wolves. The encircling 
International Journal of Mathematical, Engineering and Management Sciences

Vol. 4, No. 5, 1108-1126, 2019

https://dx.doi.org/10.33889/IJMEMS.2019.4.5-088

behavior of the pack of grey wolves can be defined with the help of the following mathematical equations (Mirjalili et al., 2014):

$\vec{D}=\left|\vec{C} \cdot \vec{X}_{P}(t)-\vec{X}(t)\right|$

$\vec{X}(t+1)=\overrightarrow{X_{P}}(t)-\vec{A} \cdot \vec{D}$

Here $\vec{X}_{P}$ and $\vec{X}$ denoted the position vector of the pray and the position vector of a grey wolf.

' $t$ ' indicates the current iteration and $\vec{A} \& \vec{C}$ are the coefficient vectors which can be calculated as follows:

$$
\begin{aligned}
& \vec{A}=2 \vec{a} \cdot \overrightarrow{r_{1}}-\vec{a} \\
& \vec{C}=2 \cdot \vec{r}_{2}
\end{aligned}
$$

$r_{1}$ and $r_{2}$ are random vectors in $[0,1]$ and component of $\vec{a}$ are linearly decreasing from 2 to 0 over the course of iterations.

Hunting behavior of grey wolves can be modelled with the help of the alpha (best candidate solution), beta and delta wolves. It is supposed that they have better knowledge about the location of the prey. That is why the other search agent, including the omegas oblige to update their positions according to the position of the best search agents as per the following formulas (Mirjalili et al., 2014):

$$
\begin{aligned}
& \overrightarrow{D_{\alpha}}=\left|\overrightarrow{C_{1}} \cdot \overrightarrow{X_{\alpha}}-\vec{X}\right|, \quad \overrightarrow{D_{\beta}}=\left|\overrightarrow{C_{2} X_{\beta}}-\vec{X}\right|, \quad \overrightarrow{D_{\delta}}=\left|\overrightarrow{C_{3} X_{\delta}}-\vec{X}\right| \\
& \vec{X}_{1}=\vec{X}_{\alpha}-\overrightarrow{A_{1}} \cdot\left(\overrightarrow{D_{\alpha}}\right), \quad \vec{X}_{2}=\overrightarrow{X_{\beta}}-\overrightarrow{A_{2}} \cdot\left(\overrightarrow{D_{\beta}}\right), \quad \overrightarrow{X_{3}}=\overrightarrow{X_{\delta}}-\overrightarrow{A_{3}} \cdot\left(\overrightarrow{D_{\delta}}\right) \\
& \vec{X}(t+1)=\frac{\overrightarrow{X_{1}}+\overrightarrow{X_{2}}+\vec{X}_{3}}{3}
\end{aligned}
$$

In order to propagate exploration and exploitation the parameter ' $a$ ' is decreasing from 2 to 0 . The pseudo code of the GWO Algorithm is provided in Figure 1 (Mirjalili et al., 2014). 
International Journal of Mathematical, Engineering and Management Sciences

Vol. 4, No. 5, 1108-1126, 2019

https://dx.doi.org/10.33889/IJMEMS.2019.4.5-088

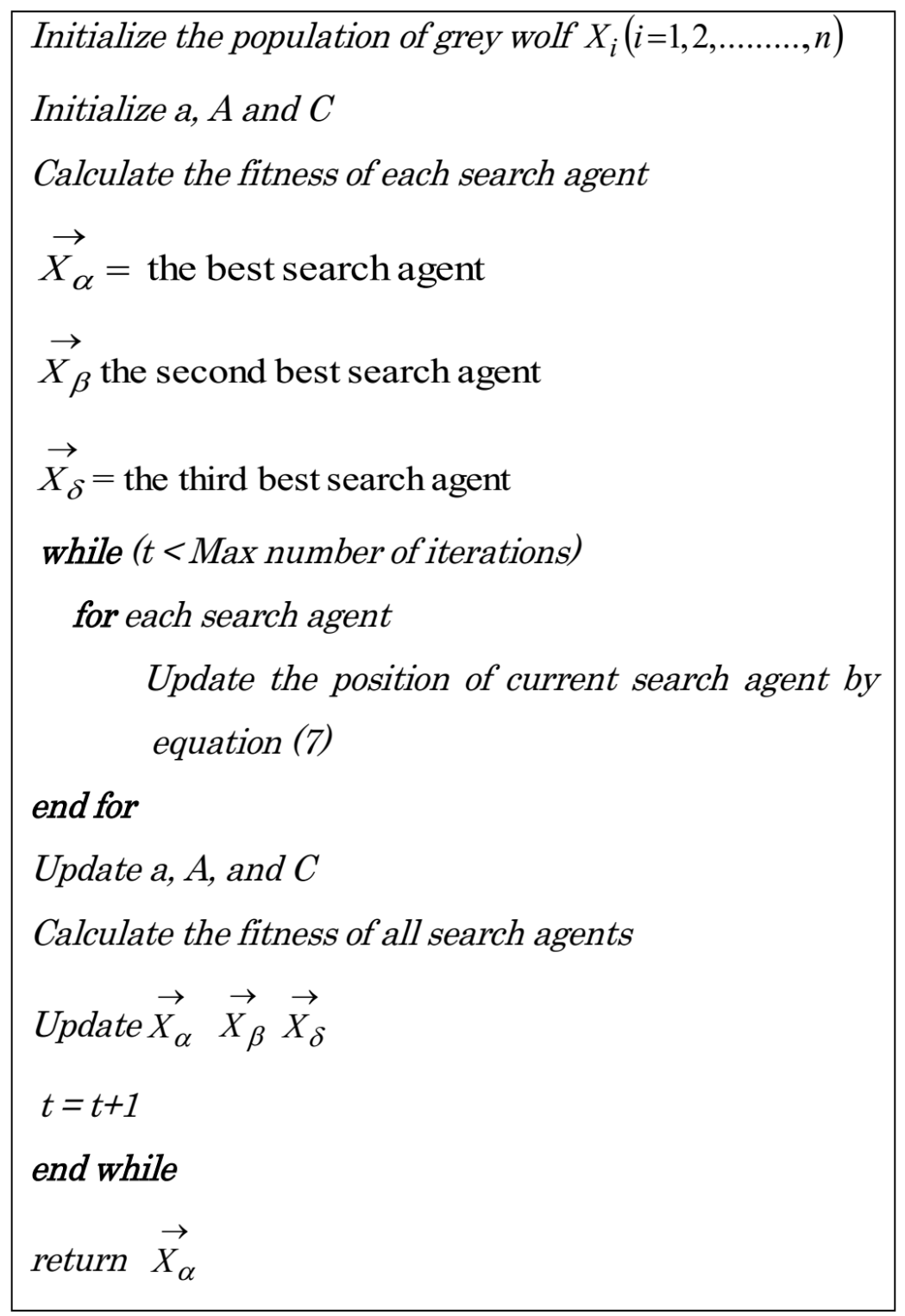

Figure 1. Pseudo code of the GWO algorithm

\subsection{Multi-Objective Particle Swarm Optimization}

The PSO algorithm, proposed by Eberhart and Kennedy (1995), is used for solving optimization problems (Pant and Singh, 2011; Pant et al. 2015b, Adewumi and Arasomwan, 2016). It is inspired from the food searching behavior of birds flocking or fish schooling. The initialization process in PSO is started with an initial swarm. Initial swarm is a randomly generated population of particles. After that, a random velocity is assigned to each particle so that it can propagate in the search space and move towards optima over a number of iterations. Each particle has its own memory, so that it can remember the best position attained by it in the past. This best position is called the personal best position and denoted by $P_{b e s t}$. Each particle has its $P_{b e s t}$ and the particle 
International Journal of Mathematical, Engineering and Management Sciences

Vol. 4, No. 5, 1108-1126, 2019

https://dx.doi.org/10.33889/IJMEMS.2019.4.5-088

with the best value of fitness is called global best particle $\left(G_{b e s t}\right)$. Suppose that the search space is $\mathrm{D}$ dimensional, the $i^{\text {th }}$ particle of the population can be represented by a D-dimensional vector $\left(x_{i}^{1}, x_{i}^{2}, \ldots, x_{i}^{D}\right)^{T}$. The velocity of this particle can be represented by another $D$-dimensional vector $\left(V_{i}^{1}, V_{i}^{2}, \ldots, V_{i}^{D}\right)^{T}$. The previously best visited position of $i^{\text {th }}$ particle is denoted by $P_{i}=\left(p_{i}^{1}, p_{i}^{2}, \ldots, p_{i}^{D}\right)^{T}$ and the best particle in the swarm is denoted by $P g=\left(p_{g}^{1}, p_{g}^{2}, \ldots, p_{g}^{D}\right)^{T}$. Particles update their position in the search space with the help of the Equation (8) and Equation (9). On the basis of a particle previous velocity Equation (8) calculates a new velocity for each particle and Equation (9) updates each particle's position in the search space.

$$
\begin{aligned}
& V_{i d}^{k+1}=w V_{i d}^{k}+c_{1} r_{1}\left[p_{i d}^{k}(t)-x_{i d}(t)\right]+c_{2} r_{2}\left[p_{g}^{k}(t)-x_{i d}^{k}(t)\right] \\
& x_{i d}^{k+1}(t+1)=x_{i d}^{k}(t)+v_{i d}^{k+1}(t+1)
\end{aligned}
$$

where $k$ denotes the iteration number and $d=1,2,3 \ldots \ldots, D . w$ denotes the inertia weight which controls the momentum of particle by weighing the contribution of previous velocity. $i=1,2$, $3 \ldots . . N ; N$ is the swarm size. $r_{1}$ and $r_{2}$ random numbers uniformly distributed between $[0,1]$ and $c_{1}$ and $c_{2}$ are positive constants called acceleration coefficients.

PSO has been extended for solving the multi objective problems (MOP), which is generally known as the multi-objective particle swarm optimization (MOPSO) (Coello et al, 2004; Ghodratnama et al., 2015). The MOPSO-CD is swarm based evolutionary multi objective optimization technique which uses the crowding distance technique (Raquel and Naval, 2005; Chen et al., 2011). A flowchart showing the procedure of the MOPSO-CD is provided in Figure 2 (Hassan et al. 2005; Zhao et al., 2007). More details of MOPSO can be consulted in (Raquel and Naval, 2005; Ghodratnama et al. 2015).

\section{Description of the Problems}

This section presents the brief description of the problems investigated in this work.

(a) Two Equations, Systems with Numerical Comparisons

The following systems are considered:

$$
\begin{aligned}
\text { Problem 1: } & \begin{array}{l}
f_{1}\left(t_{1}, t_{2}\right)=\cos \left(2 t_{1}\right)-\cos \left(2 t_{2}\right)-0.4=0 \\
f_{2}\left(t_{1}, t_{2}\right)=2\left(t_{2}-t_{1}\right)+\sin \left(2 t_{2}\right)-\sin \left(2 t_{1}\right)-1.2=0
\end{array} \\
\text { Problem 2: } & \begin{array}{l}
f_{1}\left(t_{1}, t_{2}\right)=e^{t}+t_{1} t_{2}-1=0 \\
f_{2}\left(t_{1}, t_{2}\right)=\sin \left(t_{1} t_{2}\right)+t_{1}+t_{2}-1=0
\end{array}
\end{aligned}
$$

\section{(b) Illustrative Example}

In this example, a simple system of equations, having only two equations, is used. It has more than one solution. 
International Journal of Mathematical, Engineering and Management Sciences

Vol. 4, No. 5, 1108-1126, 2019

https://dx.doi.org/10.33889/IJMEMS.2019.4.5-088

Problem 3: $f_{1}\left(t_{1}, t_{2}\right)=t_{1}^{2}-t_{2}^{2}=0$

$$
f_{2}\left(t_{1}, t_{2}\right)=1-\left|t_{1}-t_{2}\right|=0 \text {. }
$$

The ability of the evolutionary approaches is illustrated to detect several solutions in a single run.

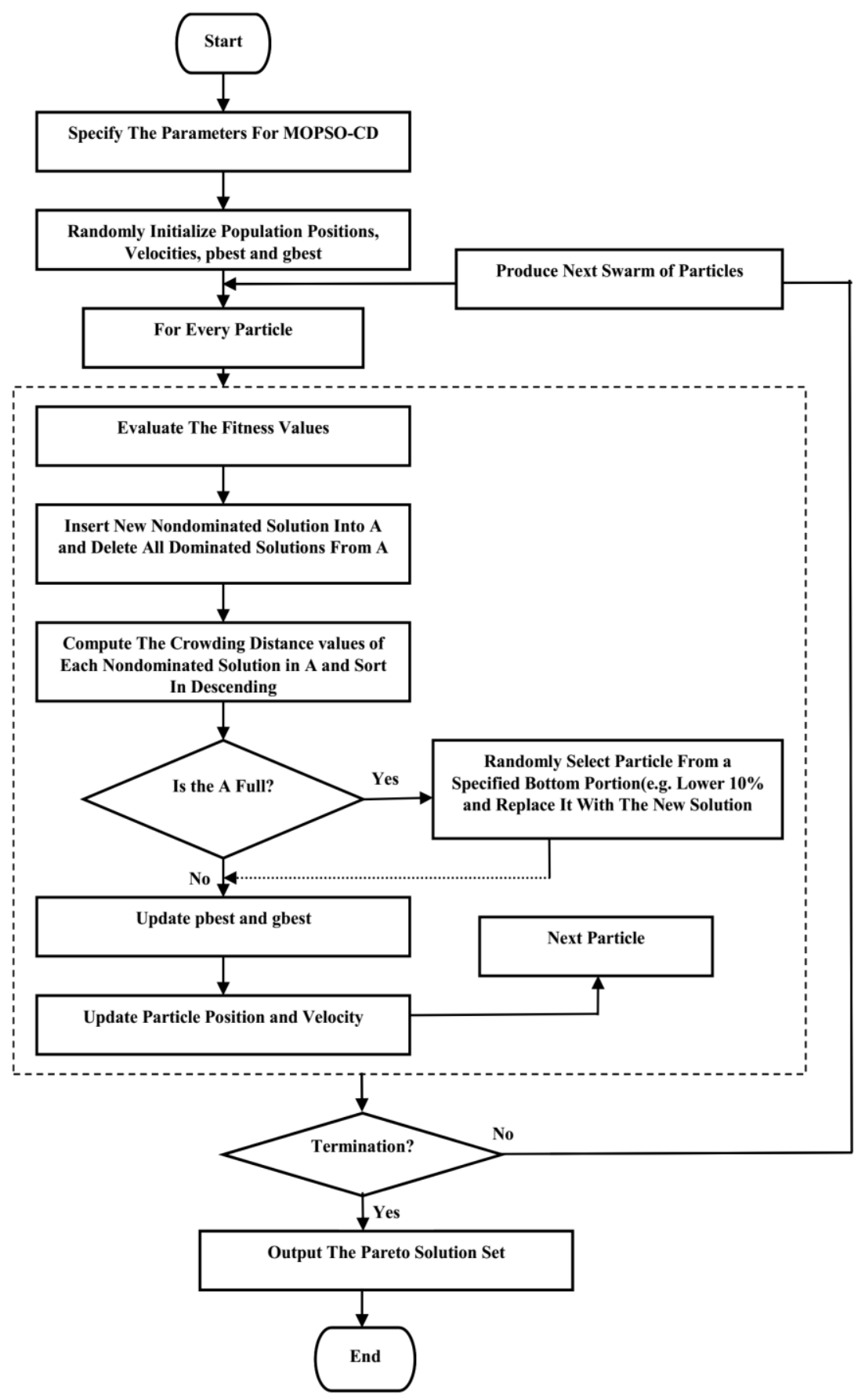

Figure 2. The flow chart of MOPSO 
International Journal of Mathematical, Engineering and Management Sciences

Vol. 4, No. 5, 1108-1126, 2019

https://dx.doi.org/10.33889/IJMEMS.2019.4.5-088

\section{(c) Neurophysiology Application}

A system of equation having more than two equations is considered (Verschelde et.al., 1994), it consists of the following equations.

$$
\begin{aligned}
f_{1} & =t_{1}{ }^{2}+t_{3}^{2}-1=0 \\
f_{2} & =t_{2}{ }^{2}+t_{4}{ }^{2}-1=0 \\
f_{3} & =t_{5} t_{3}{ }^{3}+t_{6} t_{4}{ }^{3}-c_{1}=0 \\
f_{4} & =t_{5} t_{1}{ }^{3}+t_{6} t_{2}{ }^{3}-c_{2}=0 \\
f_{5} & =t_{5} t_{1} t_{3}{ }^{2}+t_{6} t_{2} t_{4}{ }^{2}-c_{3}=0 \\
f_{6} & =t_{5} t_{3} t_{1}{ }^{2}+t_{6} t_{4} t_{2}{ }^{2}-c_{4}=0 .
\end{aligned}
$$

The constant $c_{j}$ can be randomly chosen. We have considered $c_{j}=0$ for $j=1,2,3,4$.

\section{(d) Hydrocarbon Combustion}

The equilibrium of the products of a hydrocarbon combustion process is addressed by this example. The problem is reformulated in the 'element variables' space (Maranas and Floudas, 1995; Platt, 2015).

$$
\begin{aligned}
& f_{1}=t_{1} t_{2}+t_{1}-3 t_{5}=0 \\
& f_{2}=2 t_{1} t_{2}+t_{1}+3 R_{10} t_{2}{ }^{2}+t_{2} t_{3}{ }^{2}+R_{7} t_{2} t_{3}+R_{9} t_{2} t_{4}+R_{8} t_{2}-R t_{5}=0
\end{aligned}
$$

Problem 5: $f_{3}=2 t_{2} t_{3}^{2}+R_{7} t_{2} t_{3}+2 R_{5} t_{3}^{2}+R_{6} t_{3}-8 t_{5}=0$

$$
\begin{aligned}
& f_{4}=R_{9} t_{2} t_{4}+2 t_{4}{ }^{2}-4 R t_{5}=0 \\
& f_{5}=t_{1} t_{2}+t_{1}+R_{10} t_{2}{ }^{2}+t_{2} t_{3}{ }^{2}+R_{7} t_{2} t_{3}+R_{9} t_{2} t_{4}+R_{8} t_{2}+R_{5} t_{3}{ }^{2}+R_{6} t_{3}+t_{4}{ }^{2}-1=0 .
\end{aligned}
$$

The values of parameter $R, R_{i}(\mathrm{i}=5, \ldots, 10)$ are as follows:

$$
\begin{array}{ccccccc}
\mathrm{R} & \mathrm{R}_{5} & \mathrm{R}_{6} & \mathrm{R}_{7} & \mathrm{R}_{8} & \mathrm{R}_{9} & \mathrm{R}_{10} \\
10 & 0.1930 & 0.0004106 & 0.0005451 & 0.0000004497 & 0.00003407 & 0.0000009615
\end{array}
$$

\section{Experiments and Results}

In this section, we have presented some numerical results for the problems describe in the previous section:

Table 1. Parameters used by GWO algorithm for various problems

\begin{tabular}{|c|c|c|c|c|c|}
\hline Parameter & Problem 1 & Problem 2 & Problem 3 & Problem 4 & Problem 5 \\
\hline Number of grey wolves & 30 & 30 & 30 & 30 & 30 \\
\hline Number of iterations & 200 & 200 & 200 & 200 & 200 \\
\hline Number of variables & 2 & 2 & 2 & 6 & 5 \\
\hline Lower bound & 0 & -10 & -2 & -1 & 0.0001 \\
\hline Upper bound & 1 & 10 & 2 & 1 & 100 \\
\hline
\end{tabular}


International Journal of Mathematical, Engineering and Management Sciences

Vol. 4, No. 5, 1108-1126, 2019

https://dx.doi.org/10.33889/IJMEMS.2019.4.5-088

The parameters values used by evolutionary approaches in various problems are given in Table 1 and Table 2.

Table 2. Parameters used by MOPSO for Problem 3, Problem 4 and Problem 5

\begin{tabular}{|c|c|c|c|}
\hline Parameter & Problem 3 & Problem 4 & Problem 5 \\
\hline Population size & 200 & 1000 & 500 \\
\hline Maximum generations & 500 & 200 & 500 \\
\hline Number of variables & 2 & 6 & 0.5 \\
\hline Mutation probability & 0.5 & 0.5 & 100 \\
\hline Archive size & 100 & 100 & 1.2 \\
\hline$c_{l}$ & 1.2 & 1.2 & 0.6 \\
\hline$c_{2}$ & 2 & 0.6 & 2 \\
\hline$W$ & 0.6 & & 0.6 \\
\hline
\end{tabular}

\section{(a) Two Equations Systems With Numerical Comparisons}

The results for Problem 1 and Problem 2 so obtained by applying Newton's, secant, Broyden's and Effati's methods (Grosan and Abraham, 2008) and the Grey wolf optimizer algorithm are presented in Table 3 and Table 4 respectively.

Table 3. Results for Problem 1

\begin{tabular}{|c|c|c|}
\hline Method & Solution $\left(\mathrm{t}_{1}, \mathrm{t}_{2}\right)$ & Function value $\left(\mathrm{f}_{1}, \mathrm{f}_{2}\right)$ \\
\hline Secant method & $(0.15000,0.49000)$ & $(-0.00168000,0.01497000)$ \\
\hline Newton's method & $(0.15000,0.49000)$ & $(-0.00168000,0.01497000)$ \\
\hline Effati's method & $(0.15750,0.49700)$ & $(0.00545500,0.00739000)$ \\
\hline Broyden's method & $(0.15000,0.49000)$ & $(0.00168000,0.01497000)$ \\
\hline GWO algorithm & $(0.15661,0.49355)$ & \\
\hline
\end{tabular}

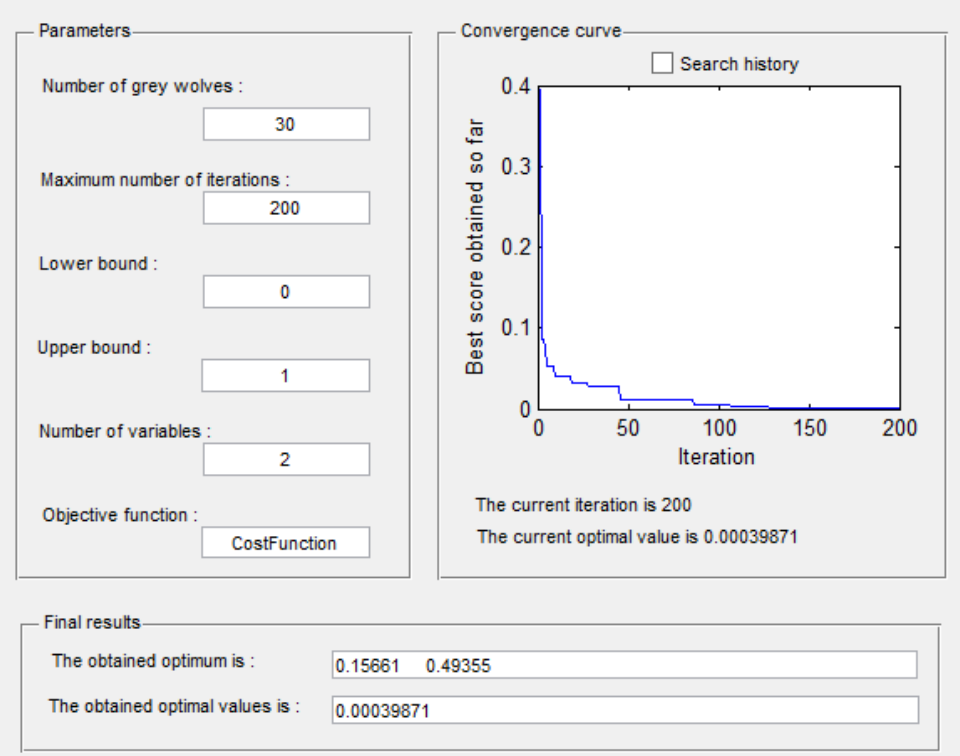

Figure 3. GWO Search history for Problem 1 
International Journal of Mathematical, Engineering and Management Sciences

Vol. 4, No. 5, 1108-1126, 2019

https://dx.doi.org/10.33889/IJMEMS.2019.4.5-088

Figure 3 and Figure 4 depicted the grey wolf optimization algorithm search history for Problem 1 and Problem 2 respectively.

Table 4. Results for Problem 2

\begin{tabular}{|c|c|c|}
\hline Method & Solution $\left(\mathrm{t}_{1}, \mathrm{t}_{2}\right)$ & Function value $\left(\mathrm{f}_{1}, \mathrm{f}_{2}\right)$ \\
\hline Effati's method & $(0.0096,0.9976)$ & $(0.019223,0.016776)$ \\
\hline GWO algorithm & $(0.000079736,0.99987)$ & $(0.000159465,0.000029462)$ \\
\hline
\end{tabular}

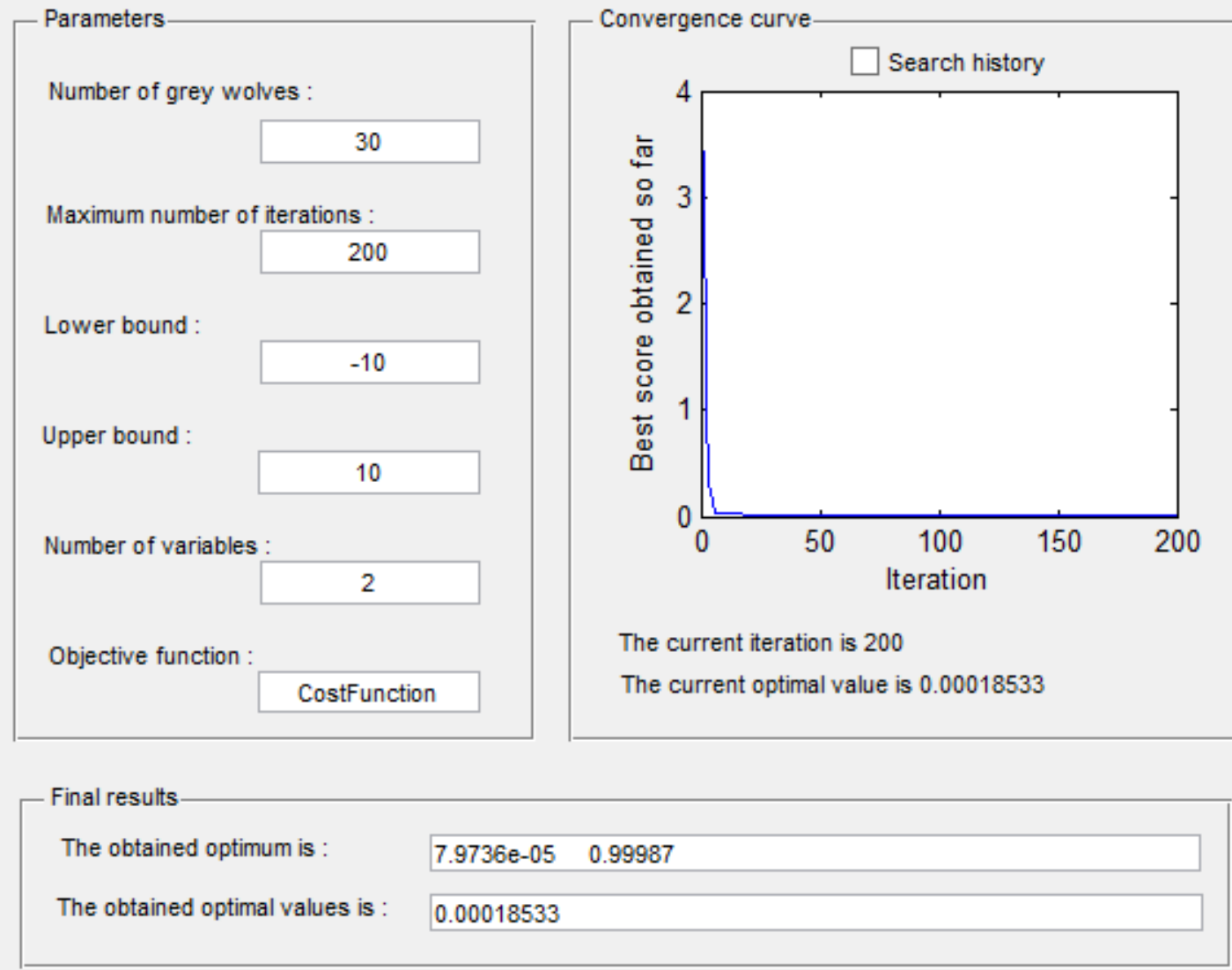

Figure 4. GWO search history for Problem 2

\section{(b) Illustrative Example}

After applying the evolutionary approach (MOPSO) on problem 3, nondominated solutions so obtained are tabulated in Table 5 and the corresponding pareto front is presented in Figure 5. The summation of objective functions absolute values so obtained for all nondominated solutions is plotted in Figure 6. 
International Journal of Mathematical, Engineering and Management Sciences

Vol. 4, No. 5, 1108-1126, 2019

https://dx.doi.org/10.33889/IJMEMS.2019.4.5-088

Table 5. Pareto front obtained by MOPSO for Problem 3

\begin{tabular}{|c|c|c|c|}
\hline \multicolumn{5}{|c|}{ Values } \\
\hline $\mathrm{t}_{1}$ & $\mathrm{t}_{2}$ & $\mathrm{f}_{1}$ & $\mathrm{f}_{2}$ \\
\hline-0.493546275 & 0.501878006 & 0.008293608 & 0.004575719 \\
\hline-0.521416877 & 0.520886147 & 0.000553181 & 0.042303024 \\
\hline-0.538965513 & 0.538890157 & 0.000081224 & 0.077855669 \\
\hline-0.527742055 & 0.527228598 & 0.000541682 & 0.054970653 \\
\hline-0.538726181 & 0.539096508 & 0.000399147 & 0.077822689 \\
\hline 0.490259625 & -0.510806013 & 0.020568283 & 0.001065639 \\
\hline 0.492800591 & -0.510952697 & 0.018220236 & 0.003753288 \\
\hline 0.496228900 & -0.495196852 & 0.001023199 & 0.008574247 \\
\hline 0.513986317 & -0.485802878 & 0.028177498 & 0.000210805 \\
\hline
\end{tabular}

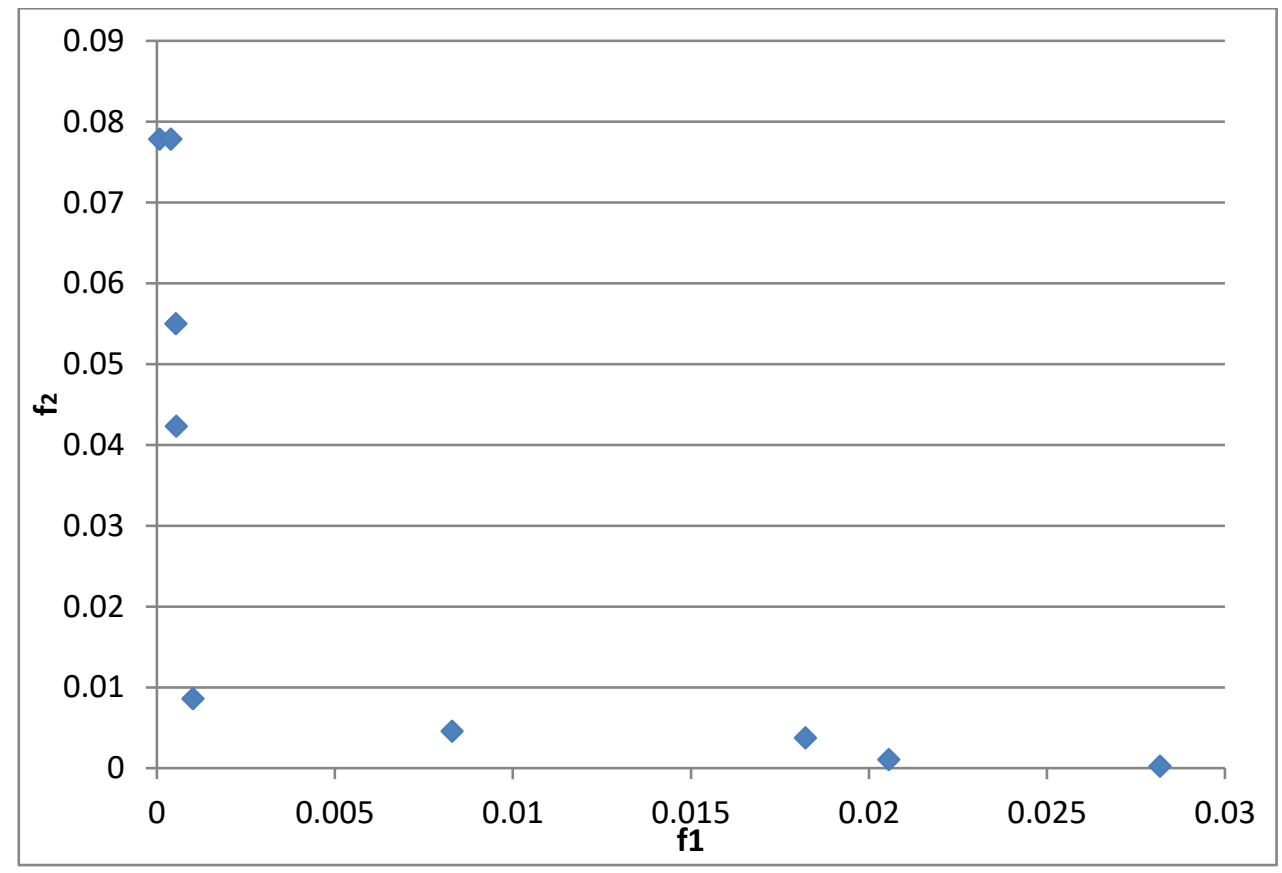

Figure 5. Pareto front obtained by MOPSO for Problem 3

Figure 7 depicts the single solution obtained for the same problem with the grey wolf optimization algorithm, after 200 iterations and with 30 grey wolves. 
International Journal of Mathematical, Engineering and Management Sciences

Vol. 4, No. 5, 1108-1126, 2019

https://dx.doi.org/10.33889/IJMEMS.2019.4.5-088

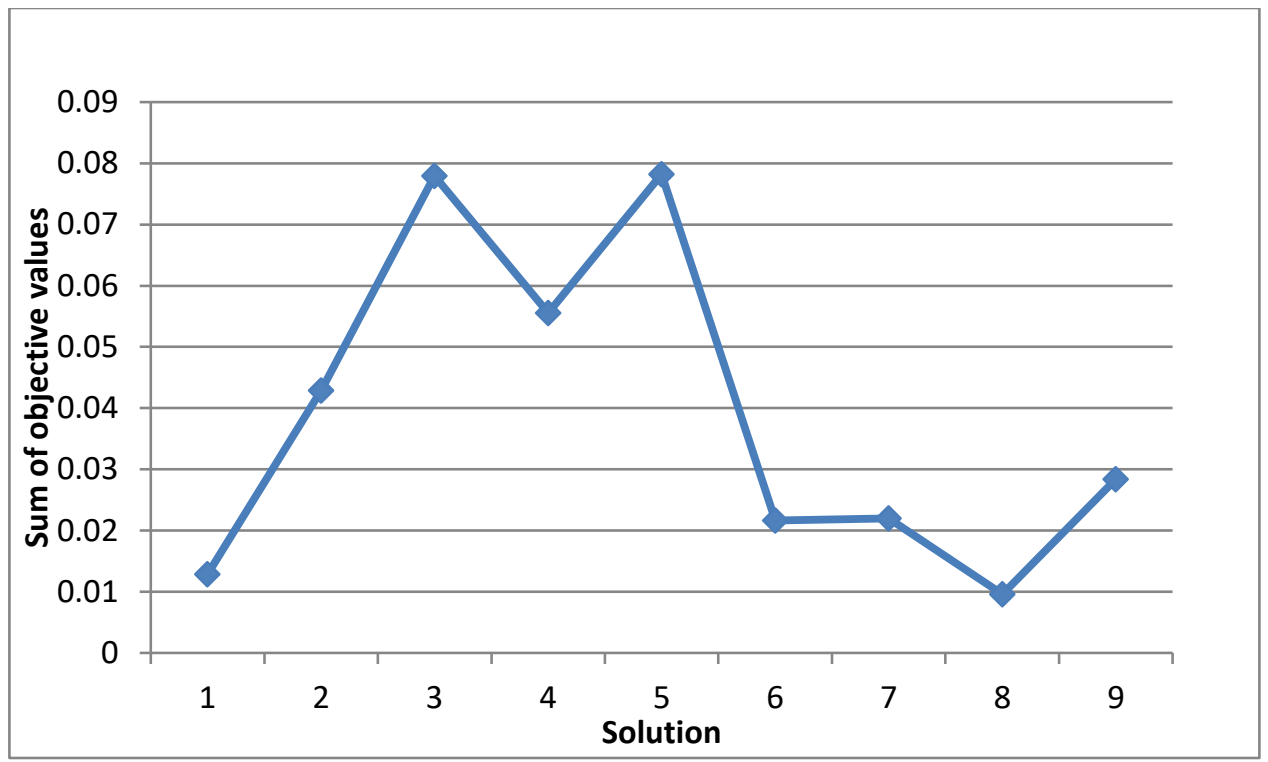

Figure 6. Summation of objective functions absolute values so obtained for all nondominated solutions corresponds to Problem 3

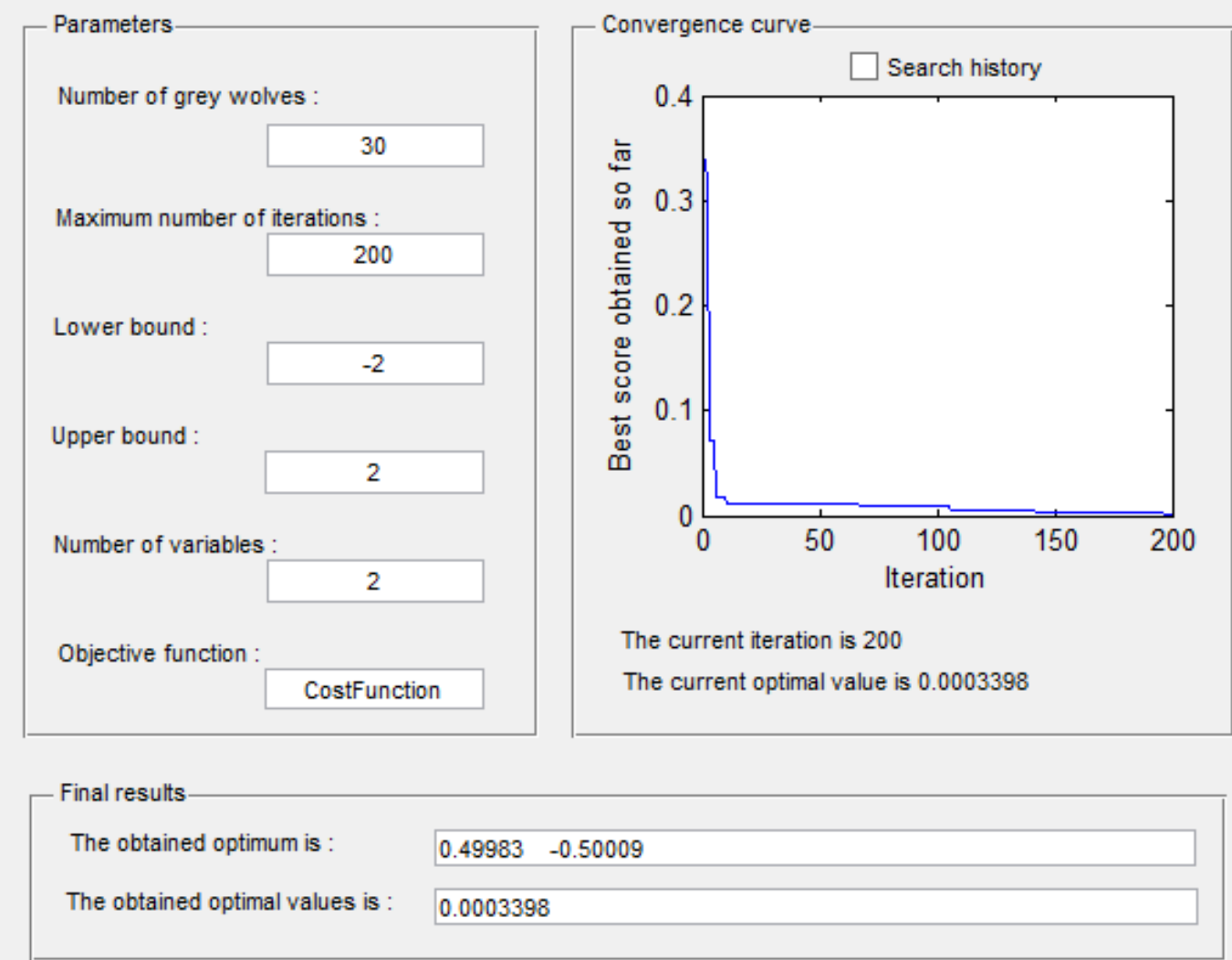

Figure 7. GWO search history for Problem 3 
International Journal of Mathematical, Engineering and Management Sciences

Vol. 4, No. 5, 1108-1126, 2019

https://dx.doi.org/10.33889/IJMEMS.2019.4.5-088

\section{(c) Neurophysiology Application}

Few nondominated solutions obtained by MOPSO for neurophysiology application are presented in Table 6 along with the values of the objectives for these values. Figure 8 represent the summation of objective functions absolute values so obtained for all nondominated solutions corresponds to neurophysiology application problem.

Table 6. Examples of nondominated solution obtained by MOPSO for neurophysiology application problem

\begin{tabular}{|c|c|c|c|c|c|}
\hline Solution & Variables values & Functions values & Solution & Variables values & Functions values \\
\hline \multirow{6}{*}{ Sol. 1} & 0.425132962 & 0.623793126 & \multirow{6}{*}{ Sol. 5} & 0.500000000 & 0.500000000 \\
\hline & 0.500000000 & 0.500000000 & & 0.500000000 & 0.518814740 \\
\hline & 0.442118580 & 0.000884430 & & 0.500000000 & 0.000276430 \\
\hline & 0.500000000 & 0.000131620 & & 0.480817280 & 0.000229740 \\
\hline & -0.078559549 & 0.000623600 & & -0.034729585 & 0.000114260 \\
\hline & 0.047237715 & 0.000372790 & & 0.036567515 & 0.000054400 \\
\hline \multirow{6}{*}{ Sol. 2} & 0.472219020 & 0.527009195 & \multirow{6}{*}{ Sol. 6} & 0.436738092 & 0.559259839 \\
\hline & 0.500000000 & 0.550399801 & & 0.500000000 & 0.500286296 \\
\hline & 0.500000000 & 0.005017868 & & 0.500000000 & 0.009105423 \\
\hline & 0.446766381 & 0.000042000 & & 0.499713622 & 0.006424150 \\
\hline & -0.100000000 & 0.003431824 & & -0.064348301 & 0.008088332 \\
\hline & 0.083904244 & 0.001778141 & & -0.008509695 & 0.007200005 \\
\hline \multirow{6}{*}{ Sol. 3} & 0.500000000 & 0.503797215 & \multirow{6}{*}{ Sol. 7} & 0.430719501 & 0.564480711 \\
\hline & 0.500000000 & 0.569759580 & & 0.500000000 & 0.624401940 \\
\hline & 0.496188255 & 0.000383500 & & 0.500000000 & 0.000162280 \\
\hline & 0.424547312 & 0.000961660 & & 0.354398166 & 0.001070940 \\
\hline & -0.021300265 & 0.000009190 & & 0.005630887 & 0.000157750 \\
\hline & 0.028993532 & 0.000435050 & & -0.012167119 & 0.000555680 \\
\hline \multirow{6}{*}{ Sol. 4} & 0.500000000 & 0.625794949 & \multirow{6}{*}{ Sol. 8} & 0.500000000 & 0.500000000 \\
\hline & 0.500000000 & 0.551570929 & & 0.500000000 & 0.500000000 \\
\hline & 0.35242737 & 0.000515985 & & 0.500000000 & 0.008424039 \\
\hline & 0.445453781 & 0.001847856 & & 0.500000000 & 0.008424039 \\
\hline & -0.040850474 & 0.000049400 & & 0.030447274 & 0.008424039 \\
\hline & 0.02606763 & 0.000696225 & & 0.036945042 & 0.008424039 \\
\hline
\end{tabular}

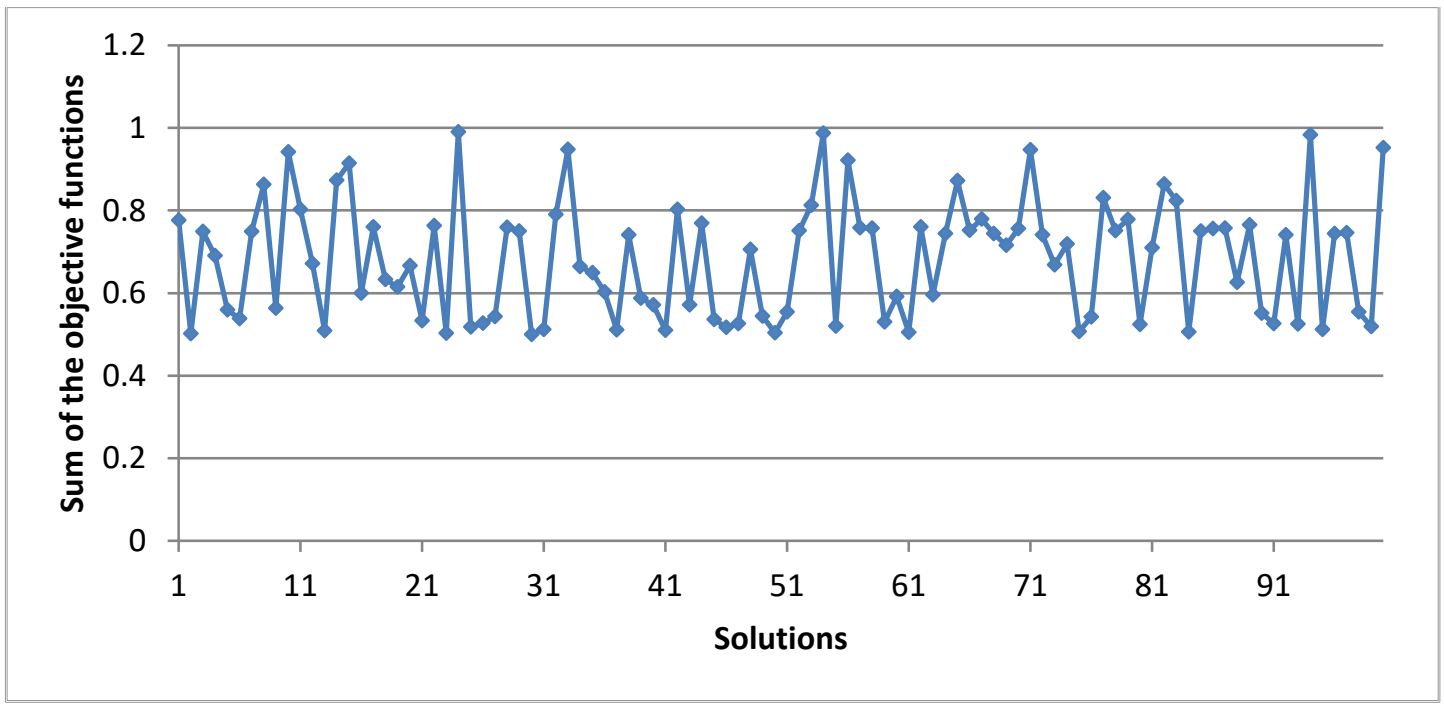

Figure 8. Summation of objective functions absolute values so obtained for all nondominated solutions corresponds to neurophysiology application problem 
International Journal of Mathematical, Engineering and Management Sciences

Vol. 4, No. 5, 1108-1126, 2019

https://dx.doi.org/10.33889/IJMEMS.2019.4.5-088

Figure 9 depicts the single solution obtained by grey wolf optimization algorithm with 30 grey wolves for neurophysiology application problem, after 200 iterations.

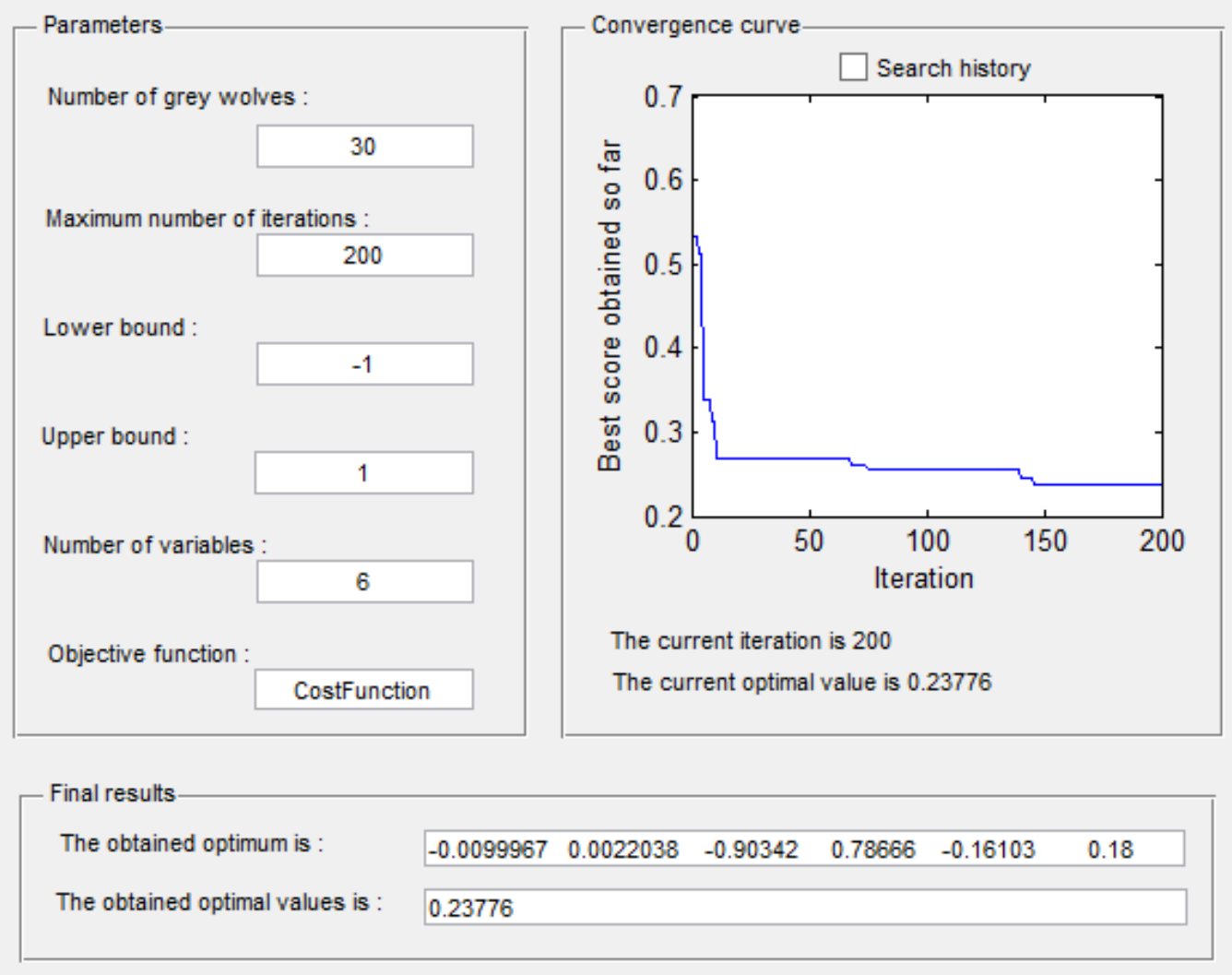

Figure 9. GWO Search history for neurophysiology application problem

\section{(d) Hydrocarbon Combustion}

Some of the nondominated solutions obtained by MOPSO for hydrocarbon combustion problem are given in Table 6 along with the values of the objectives for these values. Summation of objective functions absolute values, so obtained for all nondominated solutions correspond to this problem is depicted in Figure 10. 
International Journal of Mathematical, Engineering and Management Sciences

Vol. 4, No. 5, 1108-1126, 2019

https://dx.doi.org/10.33889/IJMEMS.2019.4.5-088

Table 7. Examples of nondominated solution obtained by MOPSO for hydrocarbon combustion problem

\begin{tabular}{|c|c|c|c|c|c|}
\hline Solution & Variables values & Functions values & Solution & Variables values & Functions values \\
\hline \multirow{5}{*}{ Sol. 1} & 0.000100 & 0.123030 & \multirow{5}{*}{ Sol. 5} & 0.000100 & 0.000183 \\
\hline & 0.128080 & 0.410342 & & 0.169164 & 0.000845 \\
\hline & 0.005977 & 0.328365 & & 0.010855 & 0.000749 \\
\hline & 0.938376 & 0.119197 & & 0.039743 & 0.000841 \\
\hline & 0.041048 & 0.044731 & & 0.000100 & 0.712090 \\
\hline \multirow{5}{*}{ Sol. 2} & 0.000100 & 0.000180 & \multirow{5}{*}{ Sol. 6} & 0.476042 & 0.573199 \\
\hline & 0.204365 & 0.000627 & & 0.204722 & 0.675497 \\
\hline & 0.033298 & 0.000340 & & 0.164255 & 0.011514 \\
\hline & 0.175599 & 0.057671 & & 0.000100 & 0.004000 \\
\hline & 0.000100 & 0.550933 & & 0.000100 & 0.003427 \\
\hline \multirow{5}{*}{ Sol. 3} & 0.132808 & 0.148442 & \multirow{5}{*}{ Sol. 7} & 0.000100 & 0.000171 \\
\hline & 0.119977 & 0.163885 & & 0.290729 & 0.045626 \\
\hline & 0.041391 & 0.000102 & & 0.399517 & 0.098117 \\
\hline & 0.050046 & 0.001009 & & 0.033073 & 0.001812 \\
\hline & 0.000100 & 0.704252 & & 0.000100 & 0.076108 \\
\hline \multirow{5}{*}{ Sol. 4} & 0.127609 & 0.149372 & \multirow{5}{*}{ Sol. 8} & 0.000100 & 0.000159 \\
\hline & 0.172897 & 0.171532 & & 0.408334 & 0.000345 \\
\hline & 0.067597 & 0.001105 & & 0.033727 & 0.000308 \\
\hline & 0.042647 & 0.000362 & & 0.084631 & 0.010326 \\
\hline & 0.000100 & 0.547869 & & 0.000100 & 0.675375 \\
\hline
\end{tabular}

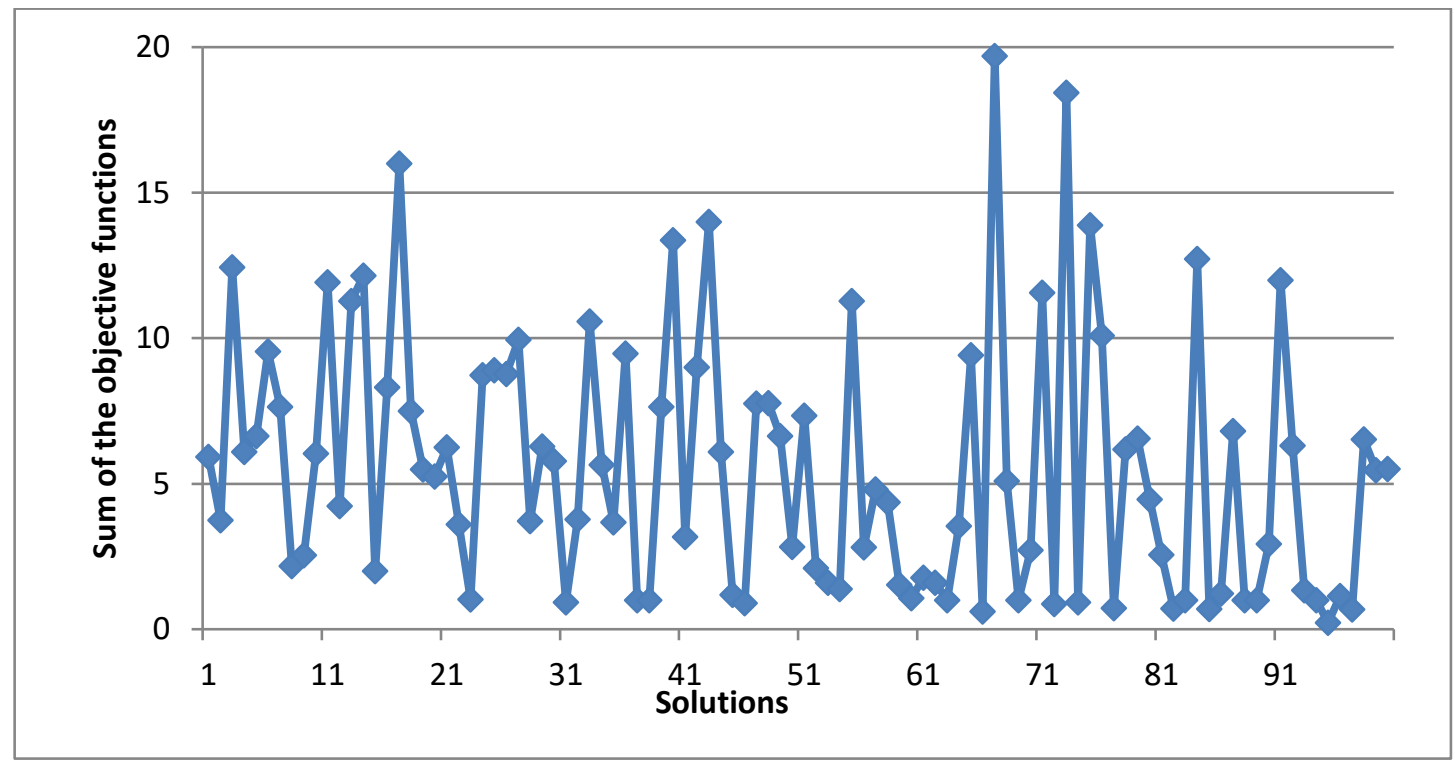

Figure 10. Summation of objective functions absolute values so obtained for all nondominated solutions corresponds to hydrocarbon combustion problem

Figure 11 reflects the single solution obtained for hydrocarbon combustion problem by grey wolf optimization algorithm after 200 iterations and with 30 grey wolves. 
International Journal of Mathematical, Engineering and Management Sciences

Vol. 4, No. 5, 1108-1126, 2019

https://dx.doi.org/10.33889/IJMEMS.2019.4.5-088

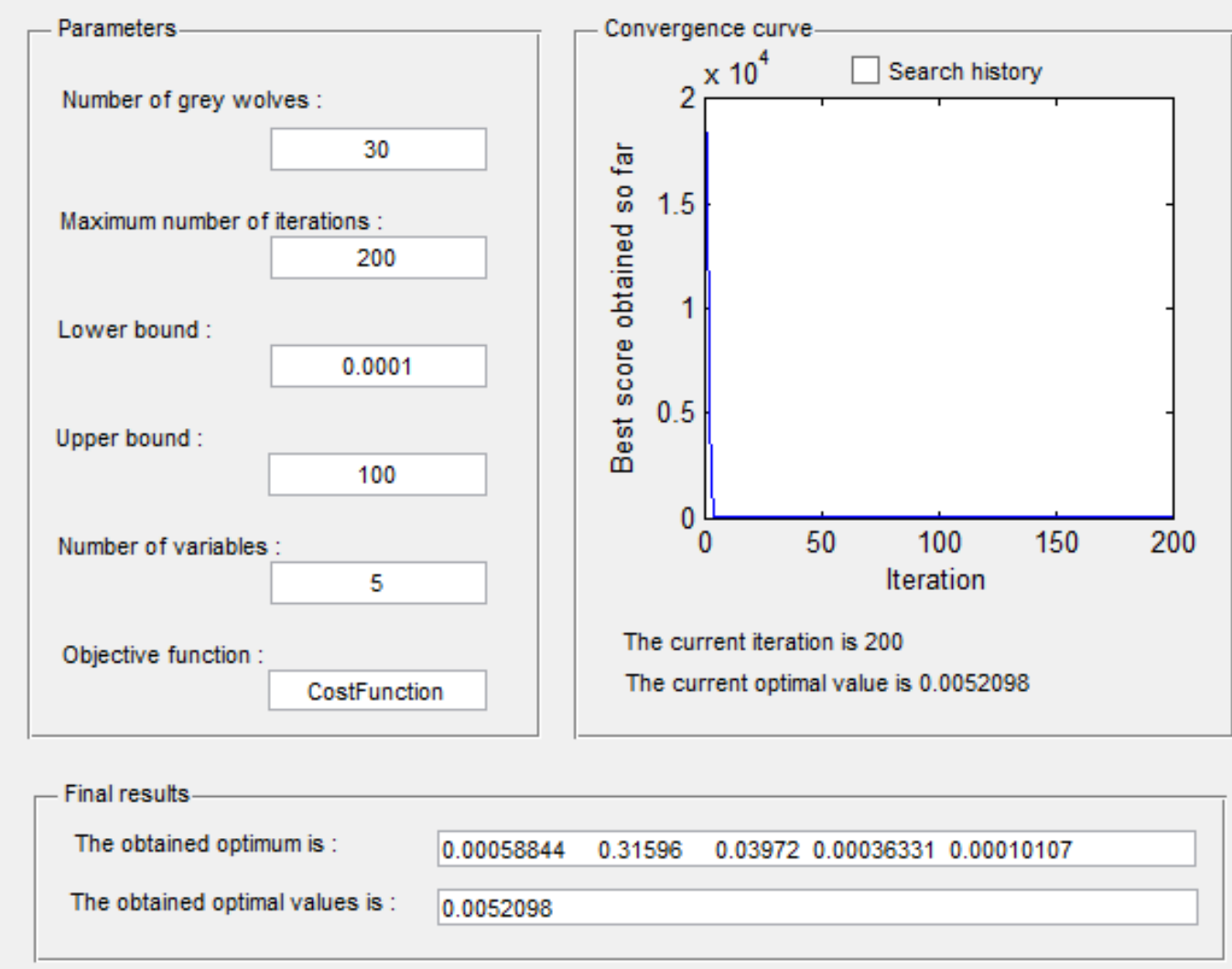

Figure 11. GWO Search history for hydrocarbon combustion problem

\section{Conclusion}

In this research, the authors have presented a framework purely based upon metaheuristics (Gogna and Tayal, 2013) for solving systems of complex nonlinear equations. The proposed framework seems to be very effective even for the problems of system of non-linear equations arises in the various fields of engineering and science. Firstly, we compared our approach for some simple equation systems having only two equations. The results obtained; presented in Table 3 and Table 4; are very competitive and clearly outperforming some classical as well as new techniques established in the literature. Then, this structure is applied to an illustrative example, having more than one solution. Several solutions which are nondominated in nature are obtained and few of them are reported in Table 5. This structure is also applied to the problem of neurophysiology application and the problem of combustion of hydrocarbons. These real life problems consist of systems having a higher number of equations. Some nondominated solutions for those problems are reported in Table 6 and Table 7. Since we transformed system of equations into a single objective/ multi objective optimization problems, our goal is to obtain values as close to zero as possible for each of the involved objective. Summation of objective functions absolute values can be considered as a measure of quality for the solution obtained. The closer the value of this summation to zero, the better the solution is. It can be clearly deducted from the graphical illustration provided in the article that the proposed framework could obtain excellent results even for some systems which are quite complicated such as neurophysiology application and combustion of hydrocarbons. 
International Journal of Mathematical, Engineering and Management Sciences

Vol. 4, No. 5, 1108-1126, 2019

https://dx.doi.org/10.33889/IJMEMS.2019.4.5-088

\section{Conflict of Interest}

The authors declare that there is no conflict of interest in this publication.

\section{Acknowledgment}

The authors acknowledge and express the gratitude to the anonymous reviewer's constructive comments and valuable suggestion towards the improvement of the paper.

\section{References}

Adewumi, A.O., \& Arasomwan, A.M. (2016). An improved particle swarm optimiser based on swarm success rate for global optimisation problems. Journal of Experimental \& Theoretical Artificial Intelligence, 28(3), 441-483.

Brezinski, C. (1997). Projection methods for systems of equations. Elsevier. Amsterdam, the Netherlands.

Broyden, C.G. (1965). A class of methods for solving nonlinear simultaneous equations. Mathematics of Computation, 19(92), 577-593.

Chaube, S., Singh, S.B., Pant, S., \& Kumar, A. (2018). Time-dependent conflicting bifuzzy set and its applications in reliability evaluation. In Advanced Mathematical Techniques in Engineering Sciences, (pp. 111-128). CRC Press.

Chen, C.B., Kuo, T.H., \& Liour, Y. (2011). Simultaneous Multi-player Game-solution Identification for Non-cooperative Advertising in Supply Chain Using MOPSO-CD and NSGA II. International Journal of Operations Research, 8(4), 19-35.

Coello, C.A.C, Pulido, G.T., \& Lechuga, M.S. (2004). Handling multiple objectives with particle swarm optimization. IEEE Transactions on Evolutionary Computation, 8(3), 256-279.

Denis, J.E. (1967a). On Newton's method and nonlinear simultaneous replacements. SIAM Journal of Numerical Analysis, 4, 103-108.

Denis, J.E., \& Wolkowicz, H. (1993). Least change secant methods, sizing, and shifting. SIAM Journal of Numerical Analysis, 30, 1291-1314.

Dennis Jr, J.E., El-Alem, M., \& Williamson, K. (1999). A trust-region approach to nonlinear systems of equalities and inequalities. SIAM Journal on Optimization, 9(2), 291-315.

Dennis, J.E. (1968b). On Newton-like methods. Numerische Mathematik, 11(4), 324-330.

Dennis, J.E. (1971c). On the convergence of Broyden's method for nonlinear systems of equations. Mathematics of Computation, 25(115), 559-567.

Eberhart, R., \& Kennedy, J. (1995). A new optimizer using particle swarm theory. In the proceeding of International Symposium on Micro Machine and Human Science, 39-43. IEEE.

Effati, S., \& Nazemi, A.R. (2005). A new method for solving a system of the nonlinear equations. Applied Mathematics and Computation, 168(2), 877-894.

Ghodratnama, A., Tavakkoli-Moghaddam, R., Kalami-Heris, S.M., \& Nagy, G. (2015). Solving a novel multi-objective uncapacitated hub location problem by five meta-heuristics. Journal of Intelligent \& Fuzzy Systems, 28(6), 2457-2469.

Gogna, A., \& Tayal, A. (2013). Metaheuristics: review and application. Journal of Experimental \& Theoretical Artificial Intelligence, 25(4), 503-526.

Grosan, C., \& Abraham, A. (2008). A new approach for solving nonlinear equations systems. IEEE Transactions on Systems, Man, and Cybernetics-Part A: Systems and Humans, 38(3), 698-714. 
International Journal of Mathematical, Engineering and Management Sciences

Vol. 4, No. 5, 1108-1126, 2019

https://dx.doi.org/10.33889/IJMEMS.2019.4.5-088

Grosan, C., Abraham, A., \& Gelbukh, A. (2006, November). Evolutionary method for nonlinear systems of equations. In Mexican International Conference on Artificial Intelligence, (pp. 283-293). Springer Berlin Heidelberg.

Hassan, R., Cohanim, B., De Weck, O., \& Venter, G. (2005, April). A comparison of particle swarm optimization and the genetic algorithm. In 46th AIAA/ASME/ASCE/AHS/ASC structures, structural dynamics and materials conference, (pp. 1897). https://doi.org/10.2514/6.2005-1897.

Hentenryck, P.V., McAllester, D., \& Kapur, D. (1997). Solving polynomial systems using a branch and prune approach. SIAM Journal of Numerical Analysis, 34(2), 797-827.

Horst, R., Pardalos, P.M., \& Thoai, N.V. (1995). Introduction to global optimization. Kluwer Academic Publishers, the Netherlands.

Kumar A., Ram M., Pant S., \& Kumar A. (2018a) Industrial system performance under multistate failures with standby mode. In: Ram M., Davim J. (eds) Modeling and Simulation in Industrial Engineering. Management and Industrial Engineering. Springer, Cham.

Kumar, A., \& Singh, S.B. (2008). Reliability analysis of an $n$-unit parallel standby system under imperfect switching using copula. Computer Modeling and New Technologies, 12(1), 47-55.

Kumar, A., Pant, S., \& Ram, M. (2017a). System reliability optimization using gray wolf optimizer algorithm. Quality and Reliability Engineering International, 33(7), 1327-1335.

Kumar, A., Pant, S., \& Singh, S.B. (2016). Reliability optimization of complex system by using cuckoos search algorithm. Mathematical Concepts and Applications in Mechanical Engineering and Mechatronics, pp. 94-110, IGI Global Publisher,

Kumar, A., Pant, S., \& Singh, S.B. (2017b). Availability and cost analysis of an engineering system involving subsystems in series configuration. International Journal of Quality \& Reliability Management, 34(6), 879-894.

Kumar, A., Pant, S., Ram, M., \& Chaube, S. (2019a). Multi-objective grey wolf optimizer approach to the reliability-cost optimization of life support system in space capsule. International Journal of System Assurance Engineering and Management, 10(2), 276-284.

Kumar, A., Pant, S., Ram, M., \& Singh, S.B. (2017c). On solving complex reliability optimization problem using multi-objective particle swarm optimization. Mathematics Applied to Engineering, pp. 115-131, Elsevier.

Kumar, A., Pant, S., \& Ram, M. (2018b). Complex system reliability analysis and optimization. Advanced Mathematical Techniques in Science and Engineering, pp. 185-199, River Publisher.

Kumar, A., Pant, S., \& Ram, M. (2019b). Gray wolf optimizer approach to the reliability-cost optimization of residual heat removal system of a nuclear power plant safety system. Quality and Reliability Engineering International. https://doi.org/10.1002/qre.2499.

Maranas, C.D., \& Floudas, C.A. (1995). Finding all solutions of nonlinearly constrained systems of equations. Journal of Global Optimization, 7(2), 143-182.

Mirjalili, S., Mirjalili, S.M., \& Lewis, A. (2014). Grey wolf optimizer. Advances in Engineering Software, 69, 46-61.

Ortega, J.M., \& Rheinboldt, W.C. (1970). Iterative solution of nonlinear equations in several variables, (Vol. 30). SIAM.

Pant, S., \& Singh, S.B. (2011, September). Particle swarm optimization to reliability optimization in complex system. In International Conference on Quality and Reliability, (pp. 211-215). IEEE.

Pant, S., Anand, D., Kishor, A., \& Singh, S.B. (2015a). A particle swarm algorithm for optimization of complex system reliability. International Journal of Performability Engineering, 11(1), 33-42. 
International Journal of Mathematical, Engineering and Management Sciences

Vol. 4, No. 5, 1108-1126, 2019

https://dx.doi.org/10.33889/IJMEMS.2019.4.5-088

Pant, S., Kumar, A., \& Ram, M. (2017a). Reliability optimization: a particle swarm approach. In Advances in Reliability and System Engineering, (pp. 163-187). Springer, Cham.

Pant, S., Kumar, A., Kishor, A., Anand, D., \& Singh, S.B. (2015b, September). Application of a multiobjective particle article swarm optimization technique to solve reliability optimization problem. In $1 s t$ International Conference on Next Generation Computing Technologies (NGCT), (pp. 1004-1007). IEEE.

Pant, S., Kumar, A., Singh, S.B., \& Ram, M. (2017b). A modified particle swarm optimization algorithm for nonlinear optimization. Nonlinear Studies, 24(1), 127-138.

Park, M., \& Pham, H. (2012). Warranty cost analysis for k-out-of- n systems with 2-D warranty, IEEE Transactions on Systems, Man, and Cybernetics-Part A: Systems and Humans, 42(4), 947-957.

Platt, G.M. (2014). Computational experiments with flower pollination algorithm in the calculation of double retrograde dew points. International Review of Chemical Engineering, 6(2), 95-99.

Platt, G.M. (2015). Application of the flower pollination algorithm in nonlinear algebraic systems with multiple solutions. Engineering Optimization IV-Rodrigues et al. (Eds), 117-121.

Press, W.H., Teukolsky, S.A., Vetterling, W.T., \& Flannery, B.P. (2002). Numerical recipes in C: the art of scientific computing. Cambridge University Press, U.K.

Ram, M. (2013). On system reliability approaches: a brief survey. International Journal of System Assurance Engineering and Management, 4(2), 101-117.

Ram, M., Singh, S.B., \& Singh, V.V. (2013). Stochastic analysis of a standby system with waiting repair strategy. IEEE Transactions on Systems, Man, and Cybernetics: Systems, 43(3), 698-707.

Raquel, C.R., \& Naval Jr, P.C. (2005, June). An effective use of crowding distance in multiobjective particle swarm optimization. In Proceedings of the 7th annual conference on Genetic and Evolutionary Computation, (pp. 257-264). ACM.

Singh, V.V., Ram, M., \& Rawal, D.K. (2013). Cost analysis of an engineering system involving subsystems in series configuration. IEEE Transactions on Automation Science and Engineering, 10(4), 1124-1130.

Verschelde, J., Verlinden, P., \& Cools, R. (1994). Homotopies exploiting Newton polytopes for solving sparse polynomial systems. SIAM Journal on Numerical Analysis, 31(3), 915-930.

Wang, D., Liu, D., Zhang, Q., \& Zhao, D. (2015). Data-based adaptive critic designs for nonlinear robust optimal control with uncertain dynamics. IEEE Transactions on Systems, Man, and Cybernetics: Systems, 46(11), 1544-1555.

Yang, S., Guo, Z., \& Wang, J. (2015). Robust synchronization of multiple memristive neural networks with uncertain parameters via nonlinear coupling. IEEE Transactions on Systems, Man, and Cybernetics: Systems, 45(7), 1077-1086.

Yang, X.S., \& Deb, S. (2009, December). Cuckoo search via Lévy flights. In 2009 World Congress on Nature \& Biologically Inspired Computing (NaBIC), (pp. 210-214). IEEE.

Zhao, J., Liu. Z., \& Dao, M. (2007). Reliability optimization using multi objective ant colony system approaches. Reliability Engineering \& System Safety, 92(1), 109-120. 